\title{
Elimination of Concentrates at Existing Reverse Osmosis Desalination Plants
}

\author{
Pervov A ${ }^{1 *}$, Andrianov A ${ }^{1}$, Rudakova $\mathrm{G}^{2}$ and Popov $\mathrm{K}^{2}$ \\ ${ }^{1}$ Department of Water Supply, Moscow State University of Civil Engineering, Russia \\ ${ }^{2} P J S C$ "Fine Chemicals R\&D Centre", Russia
}

Submission: April 12, 2017; Published: October 16, 2017

*Corresponding author: Pervov A, Department of Water Supply, Moscow State University of Civil Engineering, Russia, Email: waterlab@yandex.ru

\begin{abstract}
The existence of retentive flow discharges during reverse osmosis systems operation often creates serious ecological problems. Retentive contains all rejected dissolved salts and impurities as well as organic phosphate anticipants that does not permit to discharge it in open sources or wastewater pipelines. Concentrate flow in RO and NF applications often limits their use for drinking and industrial water production as well as for wastewater reuse due to customer's usability to handle large amounts of concentrate that cannot be discharged. The article describes principles of a new developed approach to reduce concentrate flow by means of "seeded" techniques. Results of laboratory and pilot studies to test new developed techniques and to evaluate all operational parameters of the developed membrane units are presented. Principles of evaluation of optimum process parameter values (such as: recovery, membrane rejection, membrane area, pressure, sludge amount etc.) are discussed.
\end{abstract}

Experimental procedure and laboratory test unit flow diagram is described that provides evaluation of calcium carbonate growth rates on the "seed" crystals and measures to increase scaling, such as: increase of feed water pH and amount of seeds added to the feed water. Various anticipants are tested under different conditions of RO membranes operation. To utilize RO concentrate, anticipants should provide efficient scaling prevention during well water treatment and should demonstrate low inhibition efficiency at high pH during "seed" crystals growth.

Examples of flow diagrams that completely utilize RO concentrate flow for main RO and NF applications for drinking and industrial water production as well as treatment of wastewater for its further reuse are presented. Developed equations are presented to determine main operational characteristics of membrane units (rejection prognosis, membrane surface determination, selection of anticipants, evaluation of anticipant efficiencies, "seed" technique parameters, etc.). Results of new processes pilot testing's as well as industrially applied facilities are presented.

Keywords: Reverse osmosis; Water reuse; Wastewater treatment; Concentrate disposal; Anticipants; Calcium carbonate precipitation; Seeding technique

\section{Introduction}

RO techniques are widely used for different desalination and deionization needs at industrial applications due to their high purification efficiencies and low chemical consumption. But the existence of retentate flow discharges often creates serious ecological problems. The existence of concentrate flow in RO and NF systems often limits their application area as drinking and industrial water stations often have no possibilities to handle large amounts of concentrate that cannot be discharged [1].

The existence of retentive is attributed to the fouling and scaling hazard. Increase of recovery and reduction of retentive flow causes increase of foulant concentration, super saturation of sparingly soluble salts and their precipitation in membrane channels. The use of efficient anticipants prevents scaling and enables us to increase recoveries. Synthesis of new efficient anticipants remains one of the most important solutions of RO application [2].

Modern anticipant commercial formulations contain phosphorous and nitrogen that create a hazard of evtrofication of surface water sources. To reduce environmental impact of modern desalination techniques, a new generation of "green" anticipants is now being developed that do not contain phosphorous and nitrogen and are well biodegradable and therefore reduce environmental pollution by biogenic elements [3-8]. But the use of anticipants does not exclude existence of retentate streams that cause environment pollution by salts. At present time a lot of research is devoted to development of tools to radically decrease concentrate flows to utilize it [9]. 


\section{Recent Advances in Petrochemical Science}
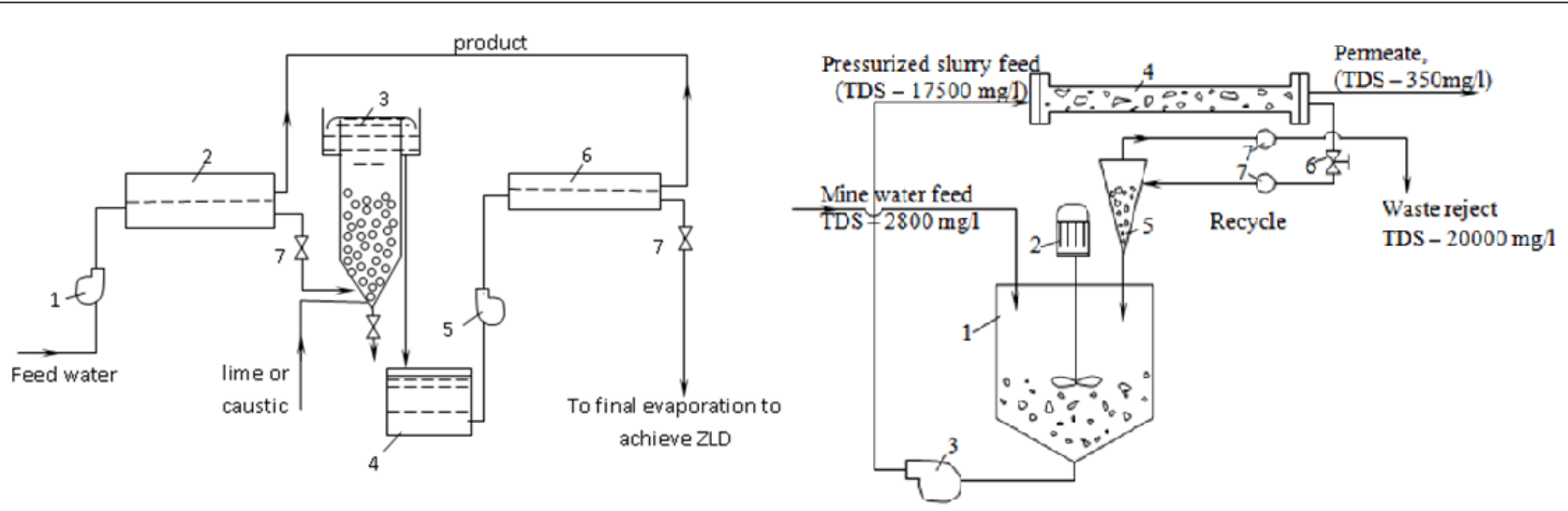

Figure 1: Modern techniques to withdraw sparingly soluble salts from RO retentive to increase recoveries:

a) A flow diagram of calcium carbonate crystallization in fluidized reactor [7]:

1-Feed pump; 2-RO module; 3-fluidized reactor; 4-softened concentrate collection tank; 5-second stage RO feed pump; 6-second stage $\mathrm{RO}$ module; 7-pressure regulation valves.

b) A flow diagram of calcium sulphate deposition on seed crystals in tubular RO system [6]:

1-seed tank; 2-stirrer; 3-feed pump; 4-RO tubular module; 5 - hydro cyclone to collect seed crystals; 6 - pressure regulation valve; 7-flow meters.

In modern practice the idea to withdraw excessive calcium from concentrate is being implemented through the use of fluidized reactor, (Figure 1a). Supersaturated solution (RO concentrate) enters reactor. To ensure high super saturation and efficient calcium carbonate precipitation, caustic is injected in the feed water entering reactor. These tools require the use of special materials (seeds, pellets) and their handling, as well as additional facilities (reactors) that require substantial capital investments and operational costs.

Control of scale formation in membrane channels can be also implemented by means of "seed" precipitation described in Addition of seed particles into RO concentrate wasimplemented in to decrease super saturation values in concentrate and to increase recoveries (Figure 1b). Described in techniques used tubular RO membrane modules. It is well known that fouling and scaling is dependent on membrane channel geometries in a new surface water nanofiltration technique is described that uses tubular membrane modules without pretreatment. The success of safe operation of nanofiltration facilities that treat surface water with high fouling potential is attributed to the use of tubular membranes and their channel geometry. Tubular modules are not widely applied due to high capital costs and low membrane surface per a unit volume of the module. Spiral wound membrane configuration is recognized as the most efficient and economically available. But strict pretreatment requirements and recovery limitations limit the use of these modules in newly developed reagent-free techniques. To overcome spiral wound disadvantages, a lot of attempts were undertaken to improve channel geometry [2]. Development of an "open channel" modules is a part of long complicated research devoted to solution of scaling control and concentrate utilization.

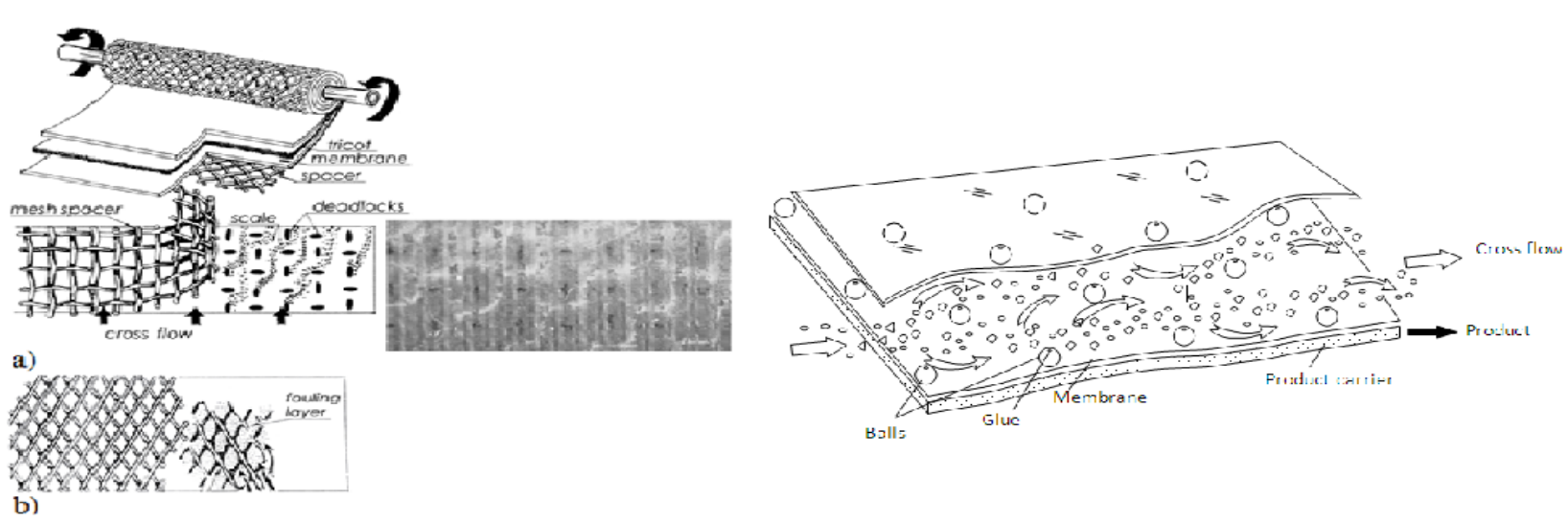

Figure 2: Fouling and scaling: influence of spacer. Formation of crystals in dead areas:

a) Formation of scale crystals:

b) Particle trapping and fouling layer formation;

c) An "open channel" configuration: seed crystals in cross-flow. 
High values of concentrate flow are mainly attributed to the "fear" of exceeding the solubility limits of main sparingly soluble constituents such as calcium sulphate and calcium carbonate in RO concentrate. The main disadvantages of spiral wound modules are attributed to the presence of separation spacer mesh in the feed channel as it traps fouling particles and increases cross-flow channel resistance. The places (spots) where the mesh connects to the membrane surface provide "dead areas" without cross-flow that result in high concentration increase at the membrane surface, initiating crystal formation (Figure 2a).

The open channel configuration is described in Technical considerations to improve membrane channel geometry and avoid formation of "dead areas". Modernization of the channel is developed by the authors and patented. Figure $2 \mathrm{~b}$ shows an "open" membrane channel where seed crystals are suspended in cross flow and are not "trapped" by the spacer mesh.

Application of new modules with "open channels" provided solution of pretreatment and concentrates utilization (recovery increase) problems in recovery of industrial desalination unit can be increased by introduction of an additional membrane step for further retentate flow decrease. This step uses "open channel" membrane modules that are operated under severe super saturation conditions. In a new technique is proposed to treat surface water or to remove iron and hardness from well water. This concept uses "open channel" membranes on the first step of feed water treatment.

Suspended and colloidal foulants (as well as iron hydroxide colloids) thatare contained in the feed water and foulmembranes are flushed off membrane surface through implementation of flushings by solenoid valves opening. Foulants are collected in sedimentation tank and after sedimentation is forwarded to dewatering. Second membrane stage is used to increase recovery and to remove suspended and colloidal foulants from retentate before it is mixed with product water. Complete RO retentate utilization was successfully implemented to treat and reuse municipal wastewater after biological treatment and storm wastewater.

Nearly all rejected by membrane impurities were withdrawn together with the sludge as a sludge moisture. High recovery (up to 0,99 ) of the second stage is limited by high retentate TDS, successful application of this proposed technique is implemented for rain (storm) water that has low TDS value. Municipal wastewater can be successfully treated directly by RO only on condition that drinking water is produced by RO and has low TDS that does not exceed 100$150 \mathrm{ppm}$. In other cases with high feed water hardness and TDS values calcium carbonate could be removed from retentive to increase recovery.

Present work describes a new developed technique to utilize retentate of existing RO facilities that produce water for industrial purposes (boiler feed, steam production etc.) To withdraw calcium carbonate from retentate and increase recovery, "seeding" technique is developed that consists of addition of "seed" crystals in RO feed water, precipitation of calcium carbonate on the "seeds", sedimentation and of excessive seeds as a sludge. This approach is described in previous publications and reports. RO retentive contains anticipants that are added to the feed water to control scaling. The presence of anticipants in the supersaturated solution inhibits calcium carbonate crystal growth. To increase calcium deposition on "seed" crystals, super saturation degree in RO retentate should be increased. Present research was aimed at investigation of calcium carbonate crystallization behavior in the presence of anticipants with a goal to remove calcium carbonate from $\mathrm{RO}$ retentate.

Additional measures are required to increase seed crystals growth. The idea to utilize concentrate in RO applications by means of "seed" techniques was described in the seed material can be produced by sedimentation of fresh crystals after addition of caustic solution to RO concentrate. Present article is aimed at investigation of operational conditions to apply "seeding" techniques to withdraw calcium carbonate RO concentrate contain anticipants. The research has several goals:

a. To study conditions of "seed" crystal growth in the presence of anticipants;

b. To determine scaling rates depending on "seed" mass, super saturation ratio, $\mathrm{pH}$ values;

c. To investigate the influence of anticipants, $\mathrm{pH}$ and other factors on crystal growth;

d. To investigate possibilities to precipitate not only calcium carbonate, but magnesium hydroxide as well;

e. To determine main operational parameters of the "seeding" process in the presence of anticipants;

f. To select suitable types of anticipants for RO operation with further concentrate utilization by means of seeding techniques.

Selection of the anticipant is determined by its behavior during desalination in conventional RO unit and during crystal growth when concentrate is treated by means of "seeding" techniques. Anticipant behavior during seed crystals growth depends on $\mathrm{pH}$ values, anticipant doses and seed crystals amount. For the further "seeding" techniques application, the anticipant used in conventional RO facility should correspond to the following requirements:

a. It should be efficient at small doses and exhibit good performance for water with small hardness and low recoveries: 
b. It should demonstrate poor performance at high $\mathrm{pH}$ values and with low doses;

\section{Experiments Materials and Methods}

The following test samples of new polymers were selected for "seeding" experiments:

a. MA/AA (copolymer of maleic and acrylic acids);

b. PASP - (polyaspartic acid sodium salt);

These industrial "green" antisacalnts have been kindly supplied by Shandong TaiHe Water Treatment Co. Ltd., and analyzed by NMR and Dynamic Light scattering technique (DLS). Conventionally used industrial anticipants were tested as reference samples.

The reference anticipant was: Aminat-K (a mixture of sodium salts of nitrilotrimethyl-phosphonic and methyliminobis-methylenephosphonic acids). Aminat-K was provided be a Russian Company "Travers". All chemicals except Aminat-K were dry (powder or crystals) and were prepared for dosage as 10 or $20 \mathrm{mg} / \mathrm{ml}$ solutions using distilled water. Water solution of MAAC was prepared by swelling in distilled water during 24 hours to obtain 1 or $2 \mathrm{mg} / \mathrm{ml}$ solutions.

All samples were synthesized and characterized (using the NMR and IR spectroscopy) by Russian company ZAO "EKOS-1". Scaling experiments were conducted in the Water treatment laboratory of Department of Water Supply, National Research Moscow State University of Civil Engineering.

Experimental program consisted of 3 experimental series:

Series 1: Preliminary anticipant performance comparison tests conducted with Moscow tap water. Selection of the most efficient product basing on scaling rates evaluation. Influence of $\mathrm{pH}$ and anticipant doses.

Series 2: Comparative studies of anticipant efficiencies during seed crystals growth. Influence of seed amount, anticipant type and $\mathrm{pH}$ on seed crystals growth.

Series 3: Investigation of influence of $\mathrm{pH}$ on precipitation of magnesium hydroxide during "seeding" techniques.

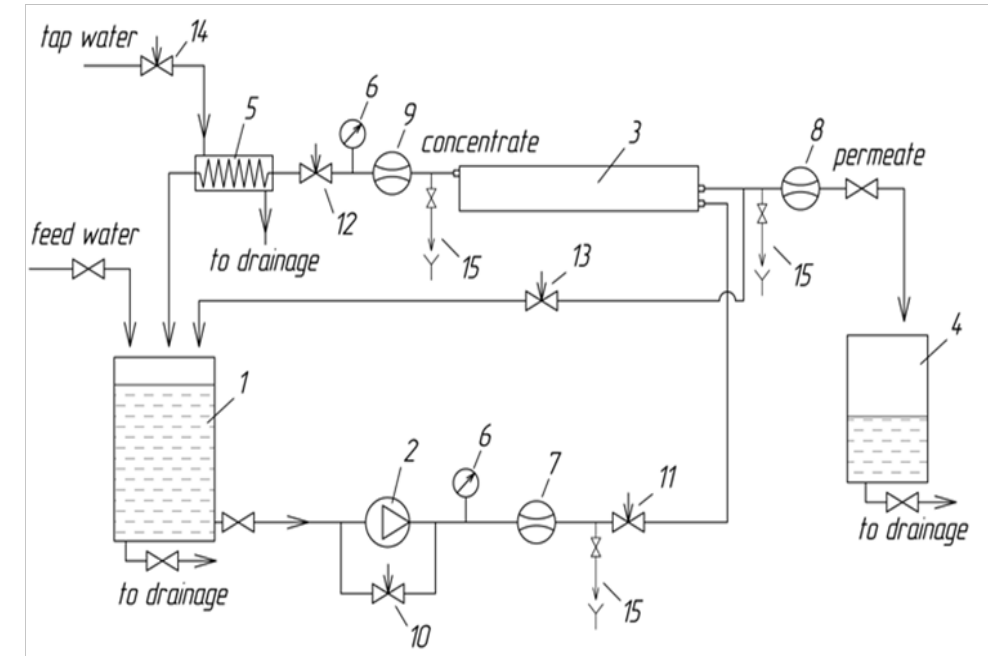

Figure 3: Schematic diagram of laboratory RO unit for membrane scaling tests:

1-feed water tank; 2-pump; 3-spiral wound membrane module; 4-permeate tank; 5-heat exchanger; 6-pressure-gauge; 7-feed water flow meter; 8-permeate flow meter; 9-concentrate flow meter; 10 - by-pass adjusting valve; 11 -feed water adjusting valve; 12 -concentrate adjusting valve; 13-cooling water adjusting valve; 14-sampler.

Membrane scaling tests were carried out using the commercial RO spiral wound membrane modules and a laboratory membrane unit shown on Figure 3 The feed solution (tap water or model solution) is placed in the feed water tank (1) and delivered to membrane module via centrifugal multistage pump (2). The trans-membrane pressure, crossflow and recovery rate is adjusted by valves $(10,11$ and 12$)$ and controlled by pressure gauges (6) and flow meters (7 and 9).

A 4040 membrane element (model ERN-B-45-300, ZAO STC "Vladipor", Russia) manufactured using ESPA membranes with rejection up to $98,5 \%(0,15 \% \mathrm{NaCl})$ was used for scaling tests. All scaling tests were conducted in circulation mode whereby reject flow (concentrate) is returned to the feed water tank (1) and permeate is collected in separate tank (4). The transmembrane pressure was maintained at 7,0 $\pm 0,2$ bar. The product flux, depending on tap water temperature, was varied from 100 to 150 liters per hour. The volume of feed solution was $80 \pm 2$ liters. Concentrate flow is kept constant at $100 \pm 10 \mathrm{l} / \mathrm{h}$ and recovery rate was in the range of 50 and $60 \%$. Experiments were carried out with Moscow tap water from April 2015 to May 2015. During this period the tap water had quite stable quality and TDS of $246 \ldots 266 \mathrm{ppm}$, total hardness of $3,1 \ldots 3,4 \mathrm{meq} / \mathrm{L}\left(155 \ldots 170 \mathrm{ppm}\right.$ of $\left.\mathrm{CaCO}_{3}\right)$, total alkalinity of $2,5 \ldots 2,9 \mathrm{meq} / \mathrm{L}$, calcium of $2,2 \ldots 2,5 \mathrm{meq} / \mathrm{L}$, $\mathrm{pH}$ of $7,75 \ldots 8,2$, sulphates of $10 \ldots 13 \mathrm{mg} / \mathrm{L}$, chlorides of $8 \ldots 10 \mathrm{mg} / \mathrm{L}$. 


\section{Recent Advances in Petrochemical Science}

The samples were taken for initial feed solution-from tank (1), for circulated solution-from tank (1) (for various concentration ratios) and for permeate-from tank (4) (one sample characterized the averaged quality of product water).

Temperature, TDS (conductivity), pH values, total hardness, total alkalinity, and calcium concentrations were determined in all samples. Conductivity and temperature was controlled by a laboratory conductivity meter Cond 730 (WTW inoLab®); pH value using laboratory pH meter HI 2215 (Hanna Instruments); total alkalinity-by titration with $\mathrm{HCl}$; total hardness and calcium-by EDTA titration. To restore membrane element performance and to remove accumulated scales every 10-15 tests chemical washing was conducted using citric acid or EDTA.
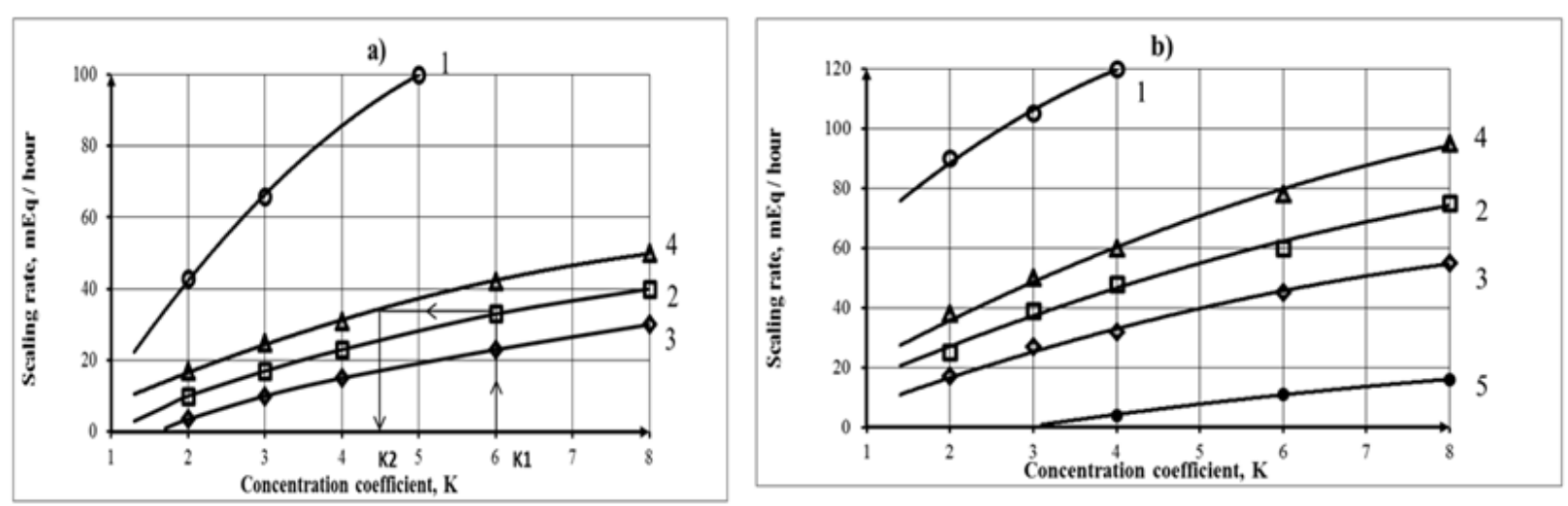

Figure 4: Determined scaling rate values (per $4040 \mathrm{R} 0$ module) versus concentration coefficient (K) values:

a) Feed water $\mathrm{pH}$ is 7,6 ;

b) Feed water $\mathrm{pH}$ is 8,9 ;

1-tap water without anticipant addition; 2-Aminat-K, 10ppm; 3-MA/AA, 10ppm; 4-PASP, 10ppm; 5- magnesium hydrohide.

The amount of scales of $\mathrm{CaCO}_{3}$ (expressed as $\mathrm{Ca}^{2+}$ in meq or $\mathrm{mg}$ ) accumulated in membrane module was calculated as a difference between initial amount of calcium in feed solution and a sum of calcium amounts in concentrate (circulating solution) and permeate Scaling rates were determined according to technique described in Figure 4 shows results of calcium carbonate scaling rates determination as dependencies of scaling rate values (defined as milliequivalents of calcium per hour per 4040 module) versus concentration coefficient (defined as feed water volume decrease ratio). Figure 4 a shows scaling rates in the presence of antiscalants in the tap water and Figure $4 \mathrm{~b}$ demonstrates increase of scaling rates at higher $\mathrm{pH}$ values.

To perform "seeding" experiments, new "open channel" spiral wound modules of 1812 standard (12" length and 1,8" in diameter) were manufactured using the BLN-type flat sheet membranes, manufactured by CSM (Korea). Modules were manufactured in accordance with configuration shown on Figure 4c using rolling machine "Model No RS 4040A" supplied by "Hydro components and Technologies", CA. Membrane surface in test modules was 0,5 sq. meter.
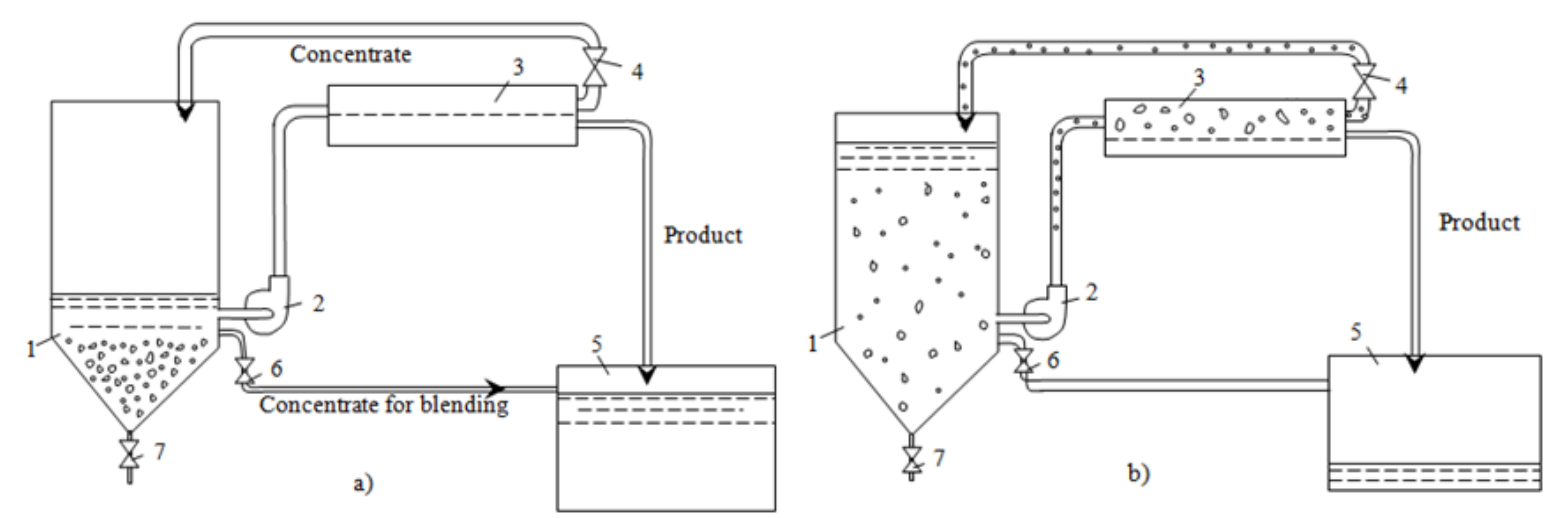

Figure 5: The idea to utilize concentrate in $\mathrm{RO}$ and a flow diagram of the test process to withdraw calcium carbonate from RO concentrate: a) "Seed" production;

b) "Seed" circulation.

1-feed water tank; 2-feed water pump; 3-RO membrane "open channel" module; 4-pressure regulation valve; 5-product water tank; 6 -concentrate valve. 
The idea to utilize concentrate in RO applications is presented on Figure 5. The seed material can be produced by sedimentation of fresh crystals after addition of caustic solution to RO concentrate (Figure 5a) Determination of required amount of seed crystals added to the feed water (seed dose) is a matter of conducted investigation. Figures 5 a $\& 5 \mathrm{~b}$ how flow diagrams of the process. After seed crystals are added to the feed water tank (1), feed water is pumped to membrane module (3). Product water is withdrawn from the system into product collect tank $[1,10]$.

Concentrate is returned back to the feed water tank 1. Calcium and carbonate ions are constantly concentrated during the test run. This provides a driving force for crystal growth. After feed water volume is decreased by 6-8 times the test unit is stopped and seed crystals sediment in the feed water tank. Calcium carbonate is withdrawn from concentrate and concentrate salinity is reduced by the value of precipitated calcium carbonate (in mill equivalents). Concentrate after sedimentation can be mixed (blended) with product water. As a result, softened water with reduced salinity, hardness and alkalinity values is obtained. These "seeding" techniques using spiral wound "open channel" modules are developed and already described in A test unit shown on Figure 3 was used. Experimental procedure was implemented using main considerations described on Figure 5. Cross flow value in the test unit was 100 liter per hour. "Seed" crystals were produced by addition of caustic solution to RO concentrate. In our experiments feed water (well water, tap water) volume was reduced by 6 times and stoichiometric amount of $1 \mathrm{~N}$ caustic solution was added to concentrate collected in flush water tank 5 to form calcium carbonate. After nucleation occurred and crystal formation phase was finished, the crystals were sedimented during 3-4 hours, collected and added to the feed water tank.

Throughout the test run feed water was constantly concentrated and samples are collected that correspond to concentration factor values 2, 3, 4, 6 and 8. Calcium and bicarbonate ionic concentrations were determined in these samples. In the end of each test run membrane "flushings" were applied that lasted 5-6 seconds. Concentrate (flush water) was collected in the tank 5. Crystals that are suspended in concentrate and removed from membrane surface sediment in tank 5 during 4-6 hours and then used in the next experimental cycle.

Thus, calcium carbonate was constantly withdrawn from the circulating solution as super saturation constantly provided a driving force for crystal growth. Small crystals sediment on membrane surface during membrane operation and are easily flushed from the membrane surface by applying "flushings". Antiscalant was added to the feed water tank 1. Antiscalant dose was $10 \mathrm{ppm}$. Caustic solution was added to the feed water to increase $\mathrm{pH}$ value. 0,7-1,5 milliequivalents of $\mathrm{NaOH}$ were added to reach 8,9-10,5 pH values.

Figure 6 shows results of experimental test runs. Figure 6a shows concentration values of calcium (in the feed water tank 1, Figure 3) versus concentration factor (initial feed water volume/volume in the tank 1). The amount of calcium carbonate seed crystals added to the feed water tank 1 was: 5 and 10 grams (150 and 300 mill equivalents respectively

The curves 2 and 4 (Figure 6) correspond to the test runs in the presence of seed crystals and antiscalant. Curves 1 and 3 show dependencies of calcium ion concentration on concentration factor for the test runs without antiscalant addition. The curves 1 demonstrates membrane modules behavior without seed addition. Results of experimental data processing are shown on Figure 7, where dependencies of scaling rates on the seed crystals doses and concentration coefficient $\mathrm{K}$ (a) and on feedwater $\mathrm{pH}$ (b) are presented. Figure 8 shows results of "seeding" experiments performed at higher $\mathrm{pH}$ values $(\mathrm{pH}=8,8)$. As it is shown, not only calcium ion is reduced in the circulation solution, but magnesium ion as well. In these experiments seed mass was produced by addition of stoichmetric amounts of caustic solution to sediment calcium carbonate and magnesium hydroxyde. In previous publications recommendations are presented to calculate seed growth rates and softening efficiencies of the developed seed techniques.

\section{Discussion of Results}

Figure 4 shows results of antiscalant efficiency testings presented as scale growth rates (mill equivalents of calcium carbonate per hour) in the standard 4040 module. Polymer MA/AA based on maleic and acrylic acids at $10 \mathrm{ppm}$ dose demonstrates best reduction of scaling rate, even better than conventionally used industrial antiscalant Aminat-K at $10 \mathrm{ppm}$. At 5ppm MA/AA does not show better performance, than Aminat-K. Polyaspartic acid (PASP) at 5ppm demonstrates similar with MA/AA efficiency, and at $10 \mathrm{ppm}$ it gives in effectiveness to MA/AA and Aminat-K. At higher $\mathrm{pH}$ values (Figure $4 \mathrm{~b}$ ) antiscalant lose their efficiencies. But at high doses (10ppm and higher) MA/AA remains the strongest antiscalant among this group. And PASP at 5ppm exhibits weakest inhibiting abilities.

It seems reasonable to use PASP antiscalant as a scale control agent at RO facilities where retentate is subsequently treated by means of "seeded" techniques. During RO retentate treatment PASP demonstrated lowest resistance to calcium carbonate precipitation. For the RO unit that treats well water, PASP provides similar antiscaing efficiency to conventional Aminat-K. To maintain scaling rate on the same level, as with Aminat-K addition, recovery (as well as concentration coefficient $K$ value) can be decreased when RO switches to PASP, as shown on Figure 4a. Figure 4a shows the way to correct $\mathrm{K}$ value when RO unit uses PASP instead of Aminat-K: 


\section{Recent Advances in Petrochemical Science}

for the designed $\mathrm{K} 1$ value of 6 that corresponds to Aminat-K dosing we determine scaling rate value and then determine $\mathrm{K} 2$ value that corresponds to scaling rate in the presence of PASP that equals 4,5 .

When "seeding" techniques to treat retentate are implemented as a second stage, decrease of $\mathrm{K}$ and recovery value on the first stage is not significant as retentate further concentrated and is utilized. When $\mathrm{pH}$ of the feed water was increased we observed magnesium hydroxide formation together with calcium carbonate. This can be explained by high pH value (and of hydroxyl ions concentration) and sufficient super saturation levels in "dead" areas of spiral wound membrane channels. Small amounts of magnesium hydroxide were always detected during membrane autopsies conducted after treatment of well water with high hardness in our experiments (Figure 6a) when tap water was treated by RO membranes, magnesium hydroxide formation was not detected or was negligible. Caustic addition to the tap water feed solution increase $\mathrm{pH}$ value up to 8,9 and also raise calcium carbonate and magnesium hydroxide precipitation rates. Addition of antiscalant does not influence magnesium
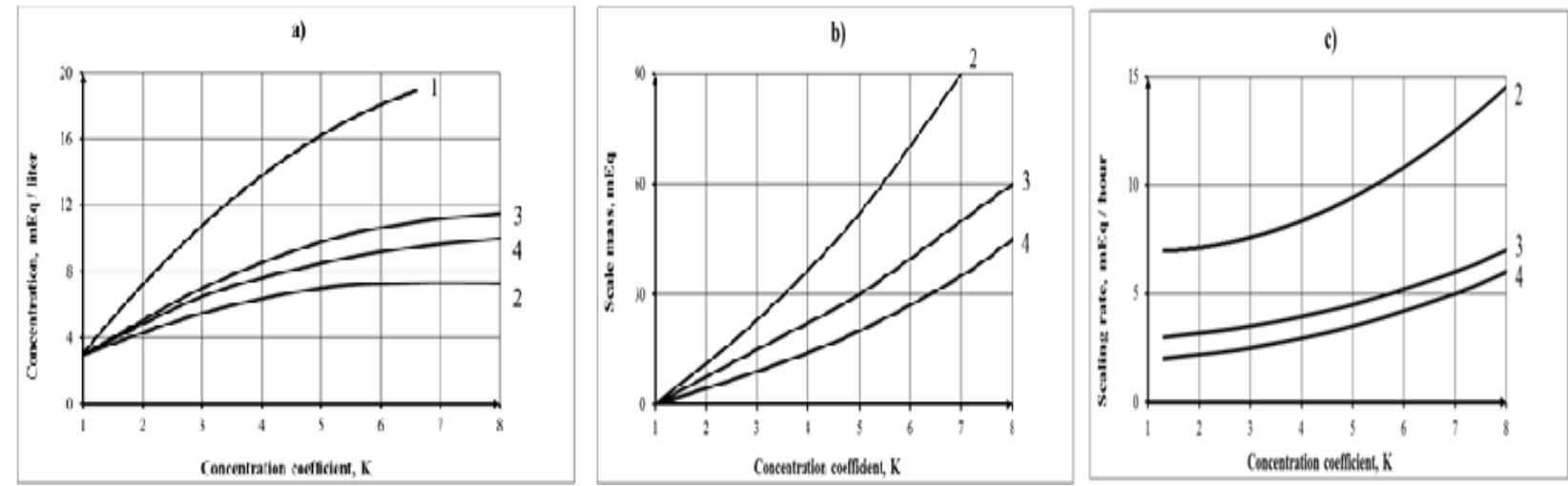

Figure 6: "Seed" crystals growth experiments in the "open channel" RO 1812 module (feed water pH is 7,7):

a) Calcium ion concentration values versus concentration coefficient (K);

b) Calcium carbonate precipitated amount versus concentration coefficient (K);

c) Calcium carbonate scaling rate versus concentration coefficient $(\mathrm{K})$;


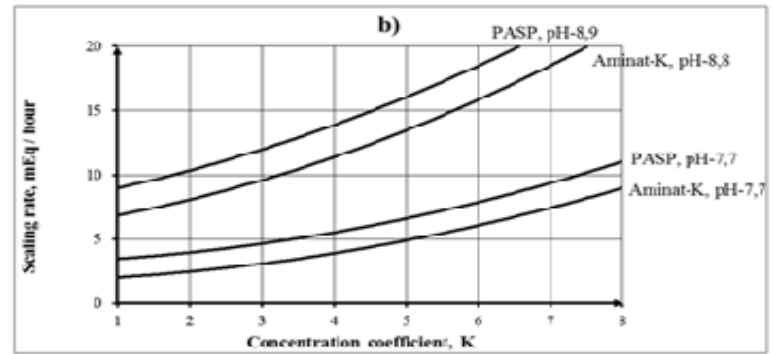

d)

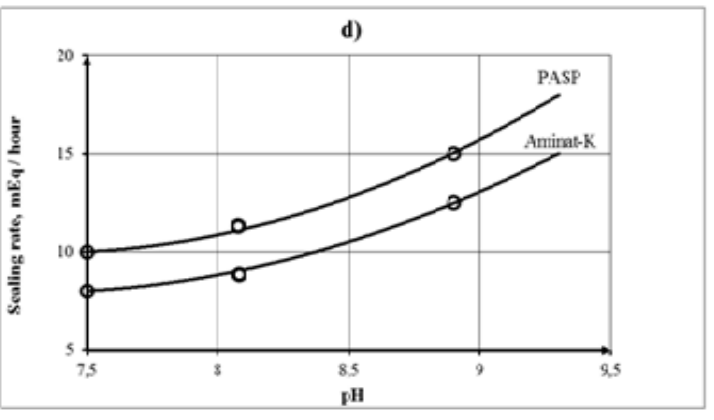

Figure 7: Influence of "seed" mass, pH value and concentration value $(K)$ on calcium carbonate "seed" crystals growth rate:

a) Scaling rate values versus concentration coefficient $(K)$ for different added "seed" amounts $(150,300,400,500$ mill equivalents);

b) Scaling rates versus concentration coefficient $(K)$ for different feed water pH values and anticipants;

c) Scaling rates versus added "seed" amounts for different $K$ values, PASP dose is $10 p p m ; Z$

d) Scaling rates versus $\mathrm{pH}$ for different anticipants, "seed" dose is $150 \mathrm{meq}$. 


\section{Recent Advances in Petrochemical Science}

Results of seed growth investigations are shown on Figures 6-8. Figure 6a shows dependencies of calcium ion concentration values in the circulating feed water solution (in the tank 1) versus the concentration factor value, which is determined as a ratio of feed water volume to concentrate volume, during a test run. Figure 6(b) shows mass of accumulated calcium carbonate versus $\mathrm{K}$. Mass of accumulated calcium carbonate was calculated as a difference between total calcium in the feed water in the beginning of experiment and total calcium in feed water concentrate. Each concentration factor value corresponds to certain time period elapsed from the beginning of experiment. Calcium carbonate growth rate is calculated as tangents of slopes of accumulated mass versus time curve
5 (Figure 6c). Addition of $10 \mathrm{ppm}$ of antiscalant decreases calcium carbonate growth rate by 3-4 times (curves $2 \& 3$ ). The increase of seed crystal mass dose by 2 times increases calcium carbonate growth rate by 3 times (for the case when antiscalant is not added, curve 4) and by 2 times in the presence of antiscalant (curve 5). Figure 7 shows influence of seed mass and $\mathrm{pH}$ values on calcium carbonate precipitation on the seed surface. Addition of 300 and 400 mill equivalents of calcium carbonate to the feed water tank substantially increases seed crystals growth Figure 8a. Addition of caustic to increase $\mathrm{pH}$ value also accelerates crystal growth Figure $8 \mathrm{~b}$. Influence of seed mass and $\mathrm{pH}$ on scaling rated are shown on Figure 8c \& 8d.
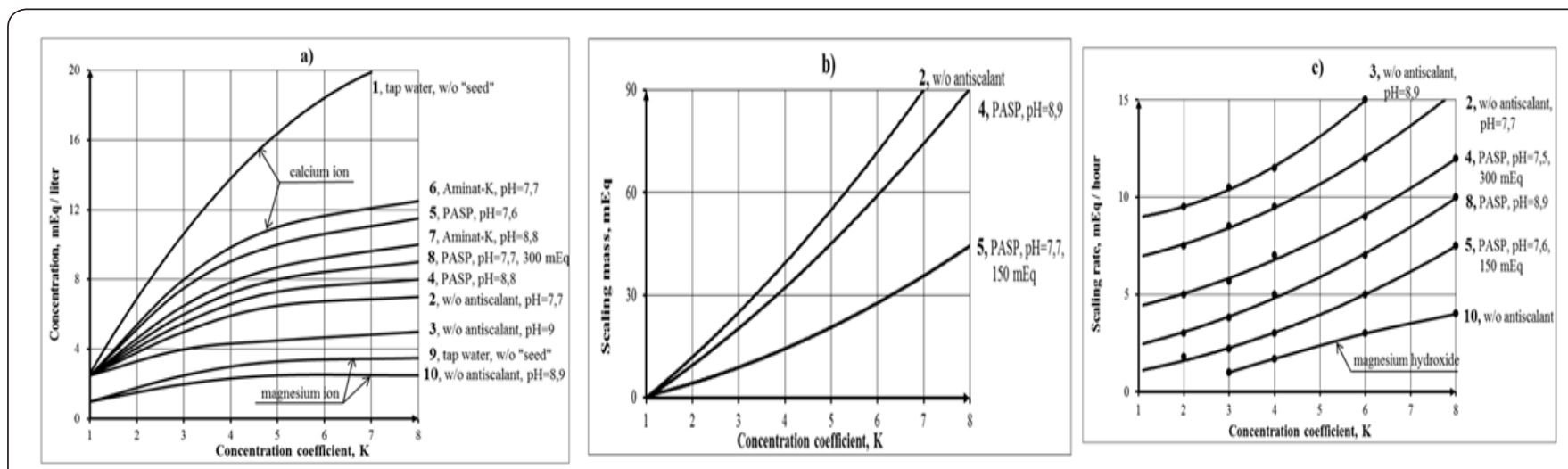

Figure 8: "Seed" crystals growth experiments. Influence of $\mathrm{pH}$ and added seed mass on scaling rate:

a) Calcium and magnesium ion concentration values versus concentration coefficient $(\mathrm{K})$;

b) Calcium carbonate precipitated amount versus concentration coefficient (K);

c) Calcium carbonate and magnesium hydroxide precipitation rate versus concentration coefficient $(\mathrm{K})$;

1-Moscow tap water without "seed" crystals;

2-"Seed" dose 150 meq, without anticipant addition, $\mathrm{pH}=7,7$;

3-"Seed" dose 200meg, (calcium carbonate + magnesium hydroxide), without anticipant addition, $\mathrm{pH}=8,9$;

4-"Seed" dose 200meq, PASP dose is $10 \mathrm{ppm}, \mathrm{pH}=8,9$;

5-"seed" dose 150meq, PASP dose is $10 \mathrm{ppm}, \mathrm{pH}=7,7$;

6-"seed" dose 150meq, Aminat-K dose is $10 \mathrm{ppm}, \mathrm{pH}=7,7$;

7-"seed" dose 200meq, Aminat-K dose is $10 \mathrm{ppm}, \mathrm{pH}=8,9$;

8-"seed" dose 300 meq, PASP dose is $10 \mathrm{ppm}, \mathrm{pH}=8,9$;

9-Magnesium ion concentration versus $\mathrm{K}$, tap water without "seed" addition;

10-Magnesium ion concentration versus K, tap water with "seed" dose 200 meq.

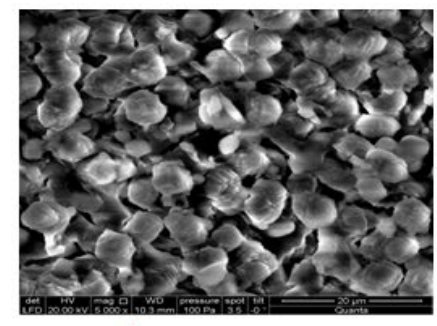

a



要

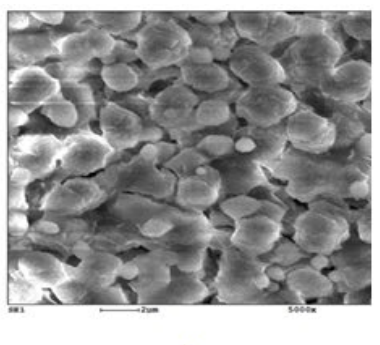

$c$

Figure 9: SEM Microphotographs of seed crystal after nucleation with different magnitudes (a, b, c).

During seed growth experiments magnesium hydroxide precipitation was detected. Figure 8a shows magnesium ion concentration versus $\mathrm{K}$ (curve 4) and magnesium hydroxide growth rateversus Kvalue is presented on Figure 6c. The driving force for magnesium hydroxide is constant concentration increase and high $\mathrm{pH}$ value. Magnesium ion concentrations were determined as a difference between total hardness and calcium concentration values. Magnesium hydroxide seeds were obtained by addition of stoic metric amount of caustic to remove hardness (to sediment calcium and magnesium). The obtained data indicates that $\mathrm{pH}$ increase of feed water during "seeding" process can successfully withdraw calcium and 


\section{Recent Advances in Petrochemical Science}

magnesium ions from RO retentate using negligible reagent amounts: caustic is used only to produce seed crystals and for $\mathrm{pH}$ value correction. SEM photos were made to investigate influence of antiscalant presence on seed crystal growth. SEM photos of crystal are shown on Figures 9 \& 10a-10C, where presence of magnesium hydroxide is detected.

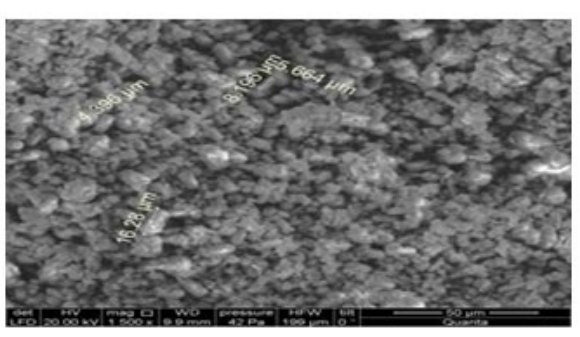

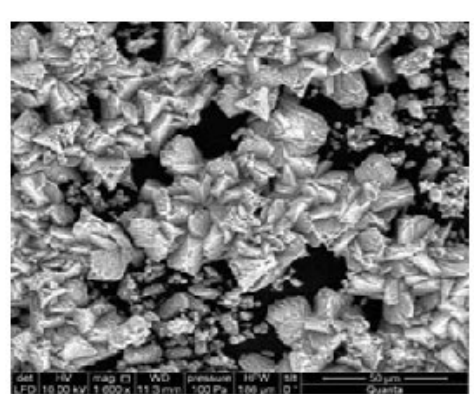

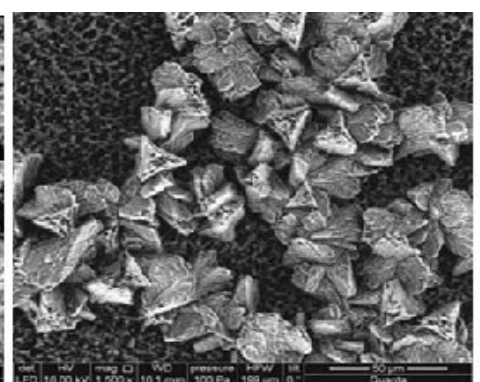

Figure 10: Microphotographs of crystals at different growth stages:

a) Crystals after nucleation;

b) Crystals after growth after 5 and 10 cycles.

c) Crystals after growth after 5 and 10 cycles.

The consumption of sodium hydroxide and required amount of calcium carbonate and magnesium hydroxide seed mass can be determined using calculation tools described in As the unit is operated in continuous mode, the amount of calcium precipitated on the circulating seed mass during one hour should correspond to scaling rate value determined experimentally for the certain feed water and recovery conditions.

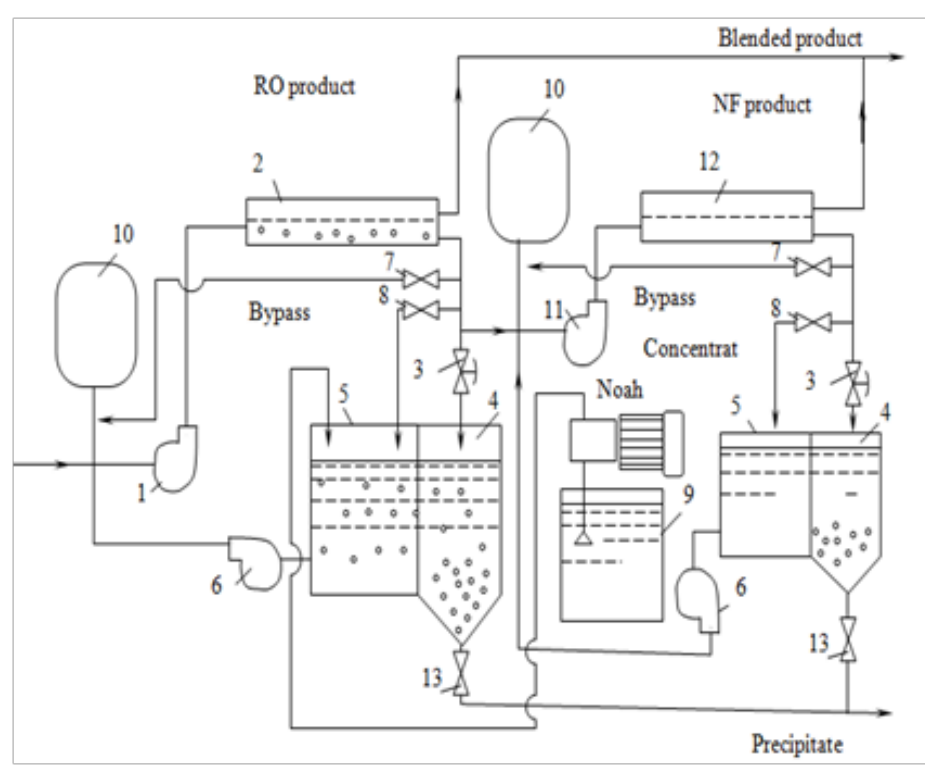

Figure 11: A flow diagram of natural water treatment with reverse osmosis membranes without concentrate discharge:

1-high pressure pump; 2-RO membrane module; 3-solenoid valve for flushing; 4-flush water sedimentation tank; 5-concentrate collection tank; 6-concentrate return pump; 7-concentrate bypass valve; 8-pressure regulation valve; 9-caustic dosing unit; 10-feed water pressure tank; 11-second stage pressure pump; 12-second stage nanofiltration membrane module; 13-precipitate discharge valve.

Blending of product and retentate flows after "seed" growth enables us to produce water with lower content of magnesium, calcium and bicarbonate ions as well as lower TDS value than existing RO retentate. As RO retentate contains "seed" crystals and possible organic and biological matter that can be withdrawn from sedimentation tank. To utilize concentrate, a second stage low rejection nanofiltration unit can be used Figure 11. Product water after nanofiltration unit is mixed with first stage RO product and concentrate is withdrawn together with precipitated calcium carbonate and magnesium hydroxide. This NF treatment aims to reject seed crystals, antiscalant and bacteria contained in RO concentrate. Low rejection nanofiltration membranes are used that poorly reject monovalent ions RO retentate after application of "seed" growth techniques can be used for technical purposes (for heating and cooling). Various ratios between treated feed water and retentate flows provide technical water with different hardness and TDS. Optimization of feed water/retentate ratio 


\section{Recent Advances in Petrochemical Science}

values provides required blended water composition with lowest costs and lowest feed water consumption.

The type of antiscalant used on the first stage in RO unit significantly influence total operational costs of RO system with retentate utilization process. Antiscalant efficiency influence scaling rate values in RO membrane modules and, therefore, antiscalant and cleaning agent's consumption. The presence of antiscalant in retentate also requires caustic to produce seed crystals and to provide high pH values to increase calcium carbonate precipitation rates. Figure 12 shows results of determination of optimum operation conditions and annual operational costs for the cases when Aminat-K (a) and PASP (b) are used in RO unit. Operational costs are presented as a function of RO concentration coefficient value $\mathrm{K}$. This value provides RO retentate flow value that is further treated by the second stage "seeding" techniques and required chemical consumption.
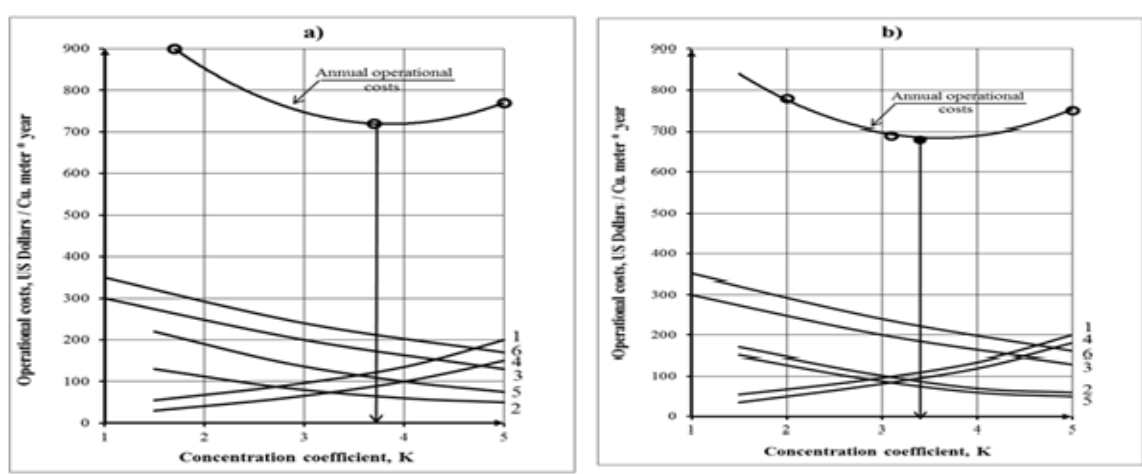

Figure 12: Determination of optimum concentration coefficient $(K)$ and annual operational costs values for Aminat-K (a) and PASP. (b) Application.

1 - Membrane replacement, 1-st stage; 2 - membrane replacement, 2-d stage; 3 - anticipant; 4 - cleaning agent; 5 - caustic (NaOH); 6 - Energy.

\section{Conclusion}

a. A new technique is described that enables us to increase recoveries and utilize RO concentrate that consists of calcium carbonate precipitation on the "seed" crystals and further blending of softened concentrate with RO product water. As a result, softened water is obtained with lower TDS and hardness than of the initial feed water.

b. Presence of antiscalants in the feed solution decreases "seed" crystals growth rates. Different antiscalants demonstrate different effect on calcium carbonate precipitation process. Selection of antiscalants for conventional RO process with further "seeding" treatment of concentrate is based on experimental determination of antiscalants efficiencies under different conditions. Polyaspartic acid (PASP) demonstrated high efficiency for well water treatment for low doses and low recoveries, and during "seed" growth at high $\mathrm{pH}$ and high seed crystals doses PASP demonstrated lowest antiscaling efficiency.

c. The increase of the seed mass increases precipitation rate. The presence of antiscalants in RO retentate significantly decrease rate of calcium carbonate precipitation on the "seed" surface. To provide efficient precipitation of calcium carbonate amount of added mass of "seed" crystals should be increased by 2-3 times.

d. Experimental relationships enable us to determine optimum values of recovery and "seed" doses to remove calcium carbonate from $\mathrm{RO}$ retentate.

\section{References}

1. Alexei Pervov (2013) Utilization of concentrate in reverse osmosis in water desalination systems. Tianjin IDA World Congress 2013 on Desalination and Water Reuse. TIAN 13: 216.

2. Potts DE, Ahlert RE, Wang S (1981) A critical review of fouling of reverse osmosis membranes. Desalination 36(3): 235-264.

3. Cohen Y (2012) Inter stage chemical demineralization for high recovery RO demineralization. The $3^{\text {rd }}$ Sede Boqer Conference on Water Technologies 2012 "Advanced Technologies in Water Management". Book of Abstracts, p. 55

4. Gilron J (2011) Flow reversal as a tool in use of crystallizer/secondary RO treatment for high recovery desalination. Ibid. pp. 56.

5. Segev R, Hasson D, Semiat R (2011) Improved high recovery brackish water desalination process based on fluidized bed air stripping. Desalination 281: 75-79.

6. Srinivas V, Bond R (2013) Getting this last drop: new technology for treatment of concentrate. Tianjin IDA World Congress 2013 on Desalination and Water Reuse. TIAN 13: 357.

7. Harries RC (1985) A field trial of seeded reverse osmosis for the desalination of a scaling-type mine water. Desalination 56: 227-236.

8. Pervov AG, Andrianov AP (2011) Application of membranes to treat wastewater for its recycling and reuse: new considerations to reduce fouling and increase recovery up to 99 per cent. Desalination and water treatment 35(1-3): 2-9.

9. Pervov AG (1991) Scale formation prognosis and cleaning procedure schedules in reverse osmosis operation. Desalination 83(1-3): 77-118.

10. Pervov A (1999) A simplified RO process design based on understanding of fouling mechanisms. Desalination 126(1-3): 227-247. 
DOI: 10.19080/RAPSCI.2017.03.555620

\section{Your next submission with Juniper Publishers will reach you the below assets}

- Quality Editorial service

- Swift Peer Review

- Reprints availability

- E-prints Service

- Manuscript Podcast for convenient understanding

- Global attainment for your research

- Manuscript accessibility in different formats ( Pdf, E-pub, Full Text, Audio)

- Unceasing customer service

Track the below URL for one-step submission https://juniperpublishers.com/online-submission.php 